\title{
Specific Susceptibility to Mucormycosis in Murine Diabetes and Bronchoalveolar Macrophage Defense against Rhizopus
}

\author{
Alayn R. Waldorf, Neil Ruderman, \\ and Richard D. Diamond \\ Evans Memorial Department of Clinical Research, and \\ Department of Medicine, University Hospital, Boston University \\ Medical Center, Boston, Massachusetts 02118
}

A

bstract. To assess the influence of diabetes mellitus in predisposing to pulmonary mucormycosis, a murine model of streptozotocin-induced diabetes was used. Intranasal inoculation of Rhizopus oryzae into diabetic mice resulted in mucormycotic infection with histopathology resembling pulmonary mucormycosis observed in humans. There was no mortality nor infection in inoculated normal mice. Diabetic mice had fatal infections caused by $R$. oryzae but significantly reduced mortality following inoculation with Aspergillus fumigatus. These findings reflect the specific enhanced susceptibility to mucormycosis observed in human diabetics.

Normal bronchoalveolar macrophages formed part of an efficient defense against $R$. oryzae by inhibiting germination, the critical step in the conversion of $R$. ory$z a e$ to its tissue invasive phase. Bronchoalveolar macrophages inhibited spore germination in vitro and appeared to help prevent germination in vivo. In contrast, spore germination occurred in diabetic mice following intranasal inoculation. Diabetic bronchoalveolar macrophages had a decreased ability to attach to hyphae. In diabetic mice, bronchoalveolar macrophages could damage spores or hyphae of $R$. oryzae, but serum factors appeared to both promote spore germination and impair attachment of macrophages to spores. This murine model of diabetes mellitus provides an opportunity for evaluation of the relative importance of cell and serum-mediated host factors in the pathogenesis of mucormycosis.

Portions of this work were presented at a meeting of the American Society for Clinical Investigation, Washington, DC, March 1983.

Received for publication 31 August 1983 and in revised form 8 March 1984.

J. Clin. Invest.

(c) The American Society for Clinical Investigation, Inc.

0021-9738/84/07/0150/11 \$1.00

Volume 74, July 1984, 150-160

\section{Introduction}

Mucormycosis in humans is rare in the absence of preexisting disease states known to affect immune competence (1). One such underlying disease is diabetes mellitus, and its specific association with mucormycosis is well documented (2). There are a variety of studies, however, with conflicting data to explain the apparent propensity of diabetics to develop mucormycotic infections (3-5). Numerous animal models using various predisposing agents and routes of inoculation have been used $(6-13)$. Often these models resulted in susceptibility to a variety of opportunistic organisms and differed markedly from mucormycosis, which typically occurs in uncontrolled human diabetics (2).

Prevention of mucormycosis requires control of either spore germination and/or hyphal growth by the host. Bronchoalveolar macrophages or monocytes are the first phagocytic cells to encounter inhaled organisms and are a primary host defense mechanism (14). We have previously shown that mononuclear and polymorphonuclear cells are capable of killing the tissueinvasive hyphal phase of Rhizopus oryzae (15-17). However, only rarely are polymorphonuclear cells observed in the histopathological pulmonary mucormycotic lesions of diabetics. Whether inhibition of spore germination and damage or killing of Rhizopus spores are caused by bronchoalveolar macrophages or other cellular or humoral components has not been determined.

To assess the influence of diabetes in predisposing to pulmonary mucormycotic infection, a murine model of diabetic mucormycosis was developed. This model provided an opportunity for evaluation of the relative importance of cell and serummediated host factors in the pathogenesis of mucormycosis. In these studies, there was a specific susceptibility of diabetic mice to pulmonary and disseminated mucormycosis. Germination of spores and infection occurred only in diabetic mice. Diabetic mouse sera allowed spore germination, and diabetic macrophages had a reduced ability to inhibit germination of $R$. oryzae spores.

\section{Methods}

Organisms. Isolates of $R$. oryzae and Aspergillus fumigatus originally obtained from patients were maintained on potato dextrose agar for 
spore and conidia harvesting (17). Viability counts for the production of inocula were determined on Sabouraud's agar (12). Hyphae were obtained by incubating $R$. oryzae spores in Sabouraud's broth at $37^{\circ} \mathrm{C}$ for $5-6 \mathrm{~h}$ until $\geq 90-95 \%$ of the spores germinated to $\geq 30 \mu \mathrm{m}$ in length as in our previous studies (17). Hyphae were stored overnight at $4^{\circ} \mathrm{C}$ before use.

Induction of diabetes. 4-6-wk-old female pathogen-free mice (Charles River CD-1 strain) weighing 20-22 g were obtained from Charles River Breeding Laboratories, Inc., Wilmington, MA. The mice were given free access to water and standard laboratory diet, except during the $8 \mathrm{~h}$ prior to streptozotocin or buffer injection when food was withdrawn.

Streptozotocin (U-9889, lot \#1180K) was used to induce diabetes (18) and was kindly supplied by Dr. William E. Dulin of the Upjohn Co. (Kalamazoo, MI). Streptozotocin was dissolved in ice-cold citrate

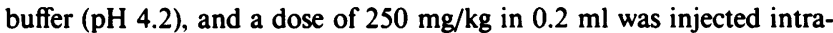
peritoneally within $10 \mathrm{~min}$ of dissolution. Control animals received 0.2 $\mathrm{ml}$ of buffer. Mice were used 7-14 $\mathrm{d}$ after streptozotocin or buffer injection.

Animal model. Graded doses of spores, conidia, or sterile aqueous inocula were administered intranasally $7 \mathrm{~d}$ following injection of streptozotocin or buffer (12). The animals were observed for $10 \mathrm{~d}$, and the cumulative mortality and 50\% lethal dose determined (19). When the animals died or were sacrificed, the organ distribution of viable fungi was determined (12). Portions of lung tissue were processed and stained with Grocott methenamine silver and hematoxylin and eosin for histological evaluation.

To determine if phagocytosis or germination of inoculated spores occurred, bronchoalveolar lavage was performed on normal and diabetic mice at $18 \mathrm{~h}$ after intranasal inoculation. Experiments done at various time intervals after inoculation and examination of stained tissue sections indicated that $18 \mathrm{~h}$ was the optimal time for lavage to recover the maximum number of ungerminated or newly germinated spores. Aseptic lavage was executed using a $1.1 \mathrm{~mm}$ (20 gauge) Angiocath (Parke, Davis and Co., Sandy, UT) for tracheal cannulation and was secured with a ligature (20). Each mouse received 3-5 1.0-ml lavages with modified Hanks balanced salt solution (HBSS) (21). Any lavage fluid contaminated with blood was discarded. Lavage fluids from three to five mice were pooled, and the alveolar lavage cells and spores were washed three times in complete HBSS and vortexed vigorously. Aliquots of $0.2 \mathrm{ml}$ samples were placed in flat-bottomed microtiter plates (Corning Glass Works, Corning, NY). The plates were centrifuged for $5 \mathrm{~min}$ at $800 \mathrm{~g}$, and spores ingested or associated with cells or spore germination were determined by direct microscopic counts using an inverted microscope (Olympus IMT, Olympus Optical Co., Tokyo, Japan). Because of the size (7-8 $\mu \mathrm{m}$ diameter) and dark pigmentation of $R$. oryzae spores, visualization of internalized and germinated spores was possible without staining. The data are expressed as the percent of spores: (number of spores associated with a cell or germinated/total number) $\times 100$. At least three experiments were done in which at least 100 spores were counted. Additional samples were incubated at $37^{\circ} \mathrm{C}$ for $5 \mathrm{~h}$ to facilitate further germination of spores.

Blood, sera, and alveolar-lining material. At the time of streptozotocin or buffer injection and 7 and $10 \mathrm{~d}$ after injection, nonfasted normal and diabetic mice inoculated with $R$. oryzae or sham inocula were exsanguinated. Whole blood $\mathrm{pH}$ was immediately measured on a radiometer, America PHM8 (Radiometer Co., Copenhagen, Denmark). Whole blood was diluted 1:1 in ice-cold $30 \%$ perchloric acid, the cells were removed by centrifugation, and the supernatant stored frozen at $-4^{\circ} \mathrm{C}$ until the glucose (22), $\beta$-hydroxybutyrate (23), and acetoacetate (24) concentrations were determined.
Sera were obtained from normal and diabetic mice at 7-10 d after injection of streptozotocin or buffer. Serum was either used immediately, or sterilized by filtration through a $0.22-\mu \mathrm{m}$ millex filter (Millipore Co., Bedford, MA) and stored frozen at $-4^{\circ} \mathrm{C}$. Spectrophotometric determination of serum iron and total iron binding capacity was performed $(25,26)$.

Alveolar-lining material was obtained by centrifuging lavage fluid at $160 \mathrm{~g}$ for $5 \mathrm{~min}$ to remove cells. The supernatant was concentrated 20 -fold by positive pressure filtration or centrifuging at $40,000 \mathrm{~g}$ and resuspending the pellet in $1 / 20$ th the original volume of HBSS (27). The $\mathrm{pH}$, glucose, acetoacetate, iron, and total iron-binding capacity were determined as above.

Bronchoalveolar macrophage-mediated inhibition of spore germination and damage to spores and hyphae in vitro. Bronchoalveolar lavage cells were harvested and pooled from 5 to 10 uninoculated normal or diabetic mice. The cells were $90.5-100 \%$ viable when assessed by exclusion of $0.1 \%$ trypan blue. Cells stained by Wright-giemsa were $\sim 80 \%$ macrophages and monocytes and the remainder of cells were lymphocytes, with $\leq 1 \%$ polymorphonuclear cells. Preliminary experiments showed that 5-24-h incubation of bronchoalveolar macrophages in complete tissue culture media (MI99 Gibco Laboratories, Grand Island, NY) caused a reversal in diabetes-associated macrophage defects. Therefore, all macrophages were used immediately upon harvesting for in vitro assays.

Bronchoalveolar macrophages were challenged in vitro with $R$. oryzae spores $(5: 1$; cell-to-spore ratio) or hyphae $(10: 1)$. These ratios were determined to be optimal for maximum attachment. The cultures, as above, were then centrifuged for $5 \mathrm{~min}$ at $800 \mathrm{~g}$ before incubation at $37^{\circ} \mathrm{C}$ for $1-6 \mathrm{~h}$ in $50 \%$ (vol/vol) fresh sera (normal or diabetic) or HBSS in flat-bottomed microtiter plates. Following incubation and vigorous vortexing, the percent of bronchoalveolar macrophages attached to spores or hyphae was measured by microscopic counts and calculated as above.

The reduction of spore germination following incubation with bronchoalveolar macrophages in vitro was determined by using a modification of the procedure of Schaffner et al. (28). Briefly, cells and $R$. oryzae spores in a 10:1 ratio, or spores alone in $50 \%(\mathrm{vol} / \mathrm{vol}$ ) fresh sera (normal or diabetic) or buffer (HBSS with $50 \mathrm{U} / \mathrm{ml}$ penicillin and $50 \mu \mathrm{g} / \mathrm{ml}$ streptomycin) were centrifuged for $5 \mathrm{~min}$ at $800 \mathrm{~g}$ and incubated for $15 \mathrm{~min}$ at $37^{\circ} \mathrm{C}$. Aliquots of $0.2 \mathrm{ml}$ samples were placed in flat-bottomed microtiter plates. The incubation was continued for a total of $5 \mathrm{~h}$ at $37^{\circ} \mathrm{C}, 5 \% \mathrm{CO}_{2}$, followed by $10 \mathrm{~h}$ at $25^{\circ} \mathrm{C}$. The plates were centrifuged for $5 \mathrm{~min}$ at $800 \mathrm{~g}$, supernatants removed, and $0.1 \mathrm{ml}$ of $2.5 \%$ deoxycholate added to lyse the macrophages. The plates were then recentrifuged and an inverted microscope was used to visualize germination. The mean germination rate was the percentage of spores forming hyphae among 100 spores counted per well from 10 replicate wells. The bronchoalveolar macrophage-induced reduction in germination rate was the difference in the means: mean control germination rate minus mean experimental germination rate.

Bronchoalveolar macrophage-mediated damage to spores and hyphae were quantitated $(16,17)$. Triplicate samples of macrophages and spores (in a 5:1 ratio) or hyphae (in a 10:1 ratio) in $50 \%$ (vol/vol) fresh sera (normal or diabetic) or HBSS were incubated at $37^{\circ} \mathrm{C}$ for $1 \mathrm{~h}$. Cell-tospore ratios of 5:1 and cell-to-hyphae ratios of 10:1 gave optimal $C^{14}$ release, presumably because of the large size of $R$. oryzae spores (7-8 $\mu \mathrm{m}$ in diameter) and hyphae (30-50 $\mu \mathrm{m}$ in length, $10-15 \mu \mathrm{m}$ in diameter). Control tubes contained only spores or hyphae in sera or HBSS during the 1-h incubation and the macrophages were added just prior to their lysis. Following macrophage lysis with $2.5 \%$ deoxycholate, spores and hyphae were washed in saline, followed by water. The remaining spores 
and hyphae were then suspended in yeast nitrogen base broth supplemented with $1 \%$ glucose and $0.15 \%$ asparagine. Each tube then received $\left[{ }^{14} \mathrm{C}\right]$ uracil $(2.0 \mu \mathrm{Ci})$ and was incubated for $2 \mathrm{~h}$ (hyphae) or $4 \mathrm{~h}$ (spores). Organisms were washed free of unbound $\left[{ }^{14} \mathrm{C}\right]$ uracil using an automated multisample harvester (Otto Hiller Co, Madison, WI), and the ${ }^{14} \mathrm{C}$ uptake was quantitated by liquid scintillation counting. Damage to spores and hyphae was calculated as the bronchoalveolar macrophage-mediated reduction in isotope uptake as in our prior studies $(16,17)$ : [(mean counts per minute in control tubes - mean counts per minute in experimental tubes)/mean counts per minute in control tubes] $\times 100$.

Respiratory burst activity of bronchoalveolar macrophages. Luminolenhanced chemiluminescence assays were performed on normal and diabetic bronchoalveolar macrophages from uninoculated mice to assess their respiratory burst potential (29). Chemiluminescence assays were performed at $2.0 \mathrm{ml}$ total volume at ambient temperature in a liquid scintillation counter (Beckman LS 100C, Beckman Instruments, Inc. Fullerton, CA) in the out-of-coincidence mode using a ${ }^{3} \mathrm{H}-{ }^{14} \mathrm{C}$-window with a gain of 2.5. Macrophages were suspended in phosphate-buffered saline with $0.1 \%$ glucose. Each plastic vial contained $1 \times 10^{5}$ macrophages, $6.7 \mathrm{mg}$ of opsonized zymosan or opsonized $R$. oryzae spores $\left(10^{5}-10^{7}\right)$, and Dulbecco's phosphate-buffered saline containing $0.1 \%$ glucose. Luminol was maintained as a stock solution $(10 \mathrm{mg} / \mathrm{ml})$ in dimethylsulfoxide and diluted just prior to use in Dulbecco's phosphate-buffered saline in $1 \mathrm{mM}$ final concentration. Sequential $0.08 \mathrm{~min}$ counts were taken on each vial over a period of $15 \mathrm{~min}$, and $0.5 \mathrm{~min}$ counts were taken for at least $1 \mathrm{~h}$. Macrophages without added zymosan or spores served as a negative control.

Superoxide production was assayed by a modification of the continuous spectrophotometric assay procedure of superoxide dismutaseinhibitable reduction of ferricytochrome $C$ to ferrocytochrome $C$ (30). Bronchoalveolar macrophages from uninoculated normal or diabetic mice were used. Reaction mixtures contained $1 \times 10^{6}$ macrophages in $1.0 \mathrm{ml}$ phosphate-buffered saline with $0.1 \mathrm{mM}$ ferricytochrome $\mathrm{C}$ and were preincubated for $3-5 \mathrm{~min}$ at $37^{\circ} \mathrm{C}$ before the addition of phorbol myristate acetate $(1 \mu \mathrm{g} / \mathrm{ml})$. Reference cuvettes contained the same components plus $60 \mu \mathrm{g}$ superoxide dismutase. Results for stimulated macrophages represent linear rates of superoxide production. The results are expressed as the mean total superoxide production in three min (nanomoles $/ 3 \mathrm{~min}$ per $10^{6}$ macrophages).

Phagosome-lysosome fusion. Evidence for fusion of lysosomes with phagosomes in normal and diabetic bronchoalveolar macrophages was by electron microscopy of acid phosphatase-labeled cells $(31,32)$. Macrophages were harvested as above except $0.1 \mathrm{M}$ cacodylate buffer, $\mathrm{pH}$ 7.4 , with $1 \% \mathrm{wt} / \mathrm{vol}$ sucrose was used. This fluid was used for all ultrastructural cytochemistry. Macrophages were inoculated with $10^{5} \mathrm{R}$. oryzae spores in 20\% normal serum and incubated for $5 \mathrm{~h}$ to allow phagocytosis and maximum acid phosphatase production.

Following incubation and washings, the macrophages were given a primary fixation of $15-20 \mathrm{~min}$ in $0.1 \mathrm{M}$ cacodylate-buffered glutaraldehyde (1.0\%) and formaldehyde (4.0\%), pH 7.4, containing $1 \% \mathrm{wt} / \mathrm{vol}$ sucrose. After fixation, cells were washed three times and then stored overnight, and refrigerated in $0.1 \mathrm{M}$ cacodylate buffer, $\mathrm{pH} 7.4$, containing $7 \% \mathrm{wt} / \mathrm{vol}$ sucrose. Ten $\mathrm{ml} 0.1 \mathrm{M}$ Tris-maleate buffer, $\mathrm{pH} 5.0,5 \mathrm{ml}$ of solution containing $25 \mathrm{mg} \mathrm{5'-cytidylic} \mathrm{acid} \mathrm{sodium,} 10 \mathrm{ml} 0.2 \% \mathrm{wt} / \mathrm{vol}$ lead nitrate, and $1.24 \mathrm{~g}$ sucrose were used for cytochemical staining. Macrophages were stained at $37^{\circ} \mathrm{C}$ for $1 \mathrm{~h}, 45 \mathrm{~min}$. After incubation and washings in $0.1 \mathrm{M}$ cacodylate buffer, macrophages were fixed as above. A secondary $1-\mathrm{h}$ fixation in $1 \% \mathrm{wt} /$ vol osmium tetroxide buffered by $0.1 \mathrm{M}$ cacodylate was followed by rapid dehydration in graded ethanols and embedding in Epon 812 (Shell Chemical Co., Houston, TX) as in our previous studies (16). Ultrathin sections through the center of the pellet were cut with diamond knives and examined with an EM 300 microscope at $80 \mathrm{kV}$ (Philips Electronic Instruments, Inc., Mahwah, NJ).

Germination in vitro. Sera were incubated overnight in $5 \% \mathrm{CO}_{2}$ to equilibrate the $\mathrm{pH}$ before germination assays. $R$. oryzae spores $\left(10^{3} /\right.$ well) were germinated in triplicate in flat-bottomed microtissue culture plates at $37^{\circ} \mathrm{C}, 5 \% \mathrm{CO}_{2}$, for 6 and $24 \mathrm{~h}$. Each well contained $180 \mu \mathrm{l}$ of alveolar-lining material (normal or diabetic), bicarbonate buffer ( $\mathrm{pH}$ 7.4), dilutions of sera (normal or diabetic), or Sabouraud's broth. Dilutions of sera or Sabouraud's broth, $10-90 \%$ (vol/vol), were made in bicarbonate buffer. In some experiments, the free iron content of $50 \%$ diabetic and normal sera was altered by the addition of ferric ammonium citrate $(0.1-200 \mu \mathrm{g} / \mathrm{dl})$ or purified human transferring $(0.1-100 \mu \mathrm{g} / \mathrm{dl}$, Sigma Chemical Co., St. Louis, MO). After the addition of iron or transferrin, sera were allowed to equilibrate for $1 \mathrm{~h}$ at $37^{\circ} \mathrm{C}, 5 \% \mathrm{CO}_{2}$, before the addition of spores. To determine the effects on spore germination, insulin (2 U/ml-20 mU/ml; PU-100, Eli Lilly Co., Indianapolis, IN) or guinea pig complement $(1.5 \mathrm{U} / \mathrm{ml}-25 \mathrm{mU} / \mathrm{ml}$, Gibco Laboratories, Grand Island, NY) were added to $50 \%$ (vol/vol) diabetic and normal sera.

Statistics. The rank sum test was used to compare infection by $R$. oryzae or $A$. fumigatus in diabetic mice (33). Where appropriate, the standard error of the natural log was used as an estimate of variance (33). Means \pm SEM were compared using the Student $t$ test for independent means (two-tailed) (33). Factorial analysis of variance (33) and Scheffe's comparison (33) were used to examine attachment and inhibition of germination by alveolar macrophages.

\section{Results}

Blood values in streptozotocin-induced diabetes. To assess the influence of diabetes in predisposing to pulmonary mucormycosis, a murine model of streptozotocin-induced diabetes was used. A mild, diabetic ketoacidosis was induced within 7 $\mathrm{d}$ after streptozotocin injection, with a decrease in the normal murine alkaline blood $\mathrm{pH}$ of 7.8 to $\mathrm{pH}$ 7.3-7.2 (Table I). Intranasal challenge of normal mice with $R$. oryzae spores also resulted in acidosis ( $\mathrm{pH}$ 7.4).

Mucormycotic infection in diabetic mice. Following intranasal inoculation, there was an increasing mortality with increasing inocula of $R$. oryzae spores (Fig. 1) or Rhizomucor pusillus (data not shown). The mean lethal dose $\left(\mathrm{LD}_{50}\right)$ was $1.2 \times 10^{4}$ and $4.1 \times 10^{4}$ colony forming units, respectively. $70 \%(38 / 54)$ of the deaths occurred between days 1 and 4 after inoculation. In contrast, there was no mortality in normal mice inoculated with $10^{6}$ colony forming units $R$. oryzae $(P<0.001$ by rank sum), nor in diabetic mice which received a sham intranasal inoculation.

Lung recoveries of $R$. oryzae spores immediately and $1 \mathrm{~h}$ after inoculation in normal and diabetic mice indicated diabetic ketoacidosis did not alter the spore inocula reaching lung tissue $\left(1.7 \times 10^{4} \pm 1.9\right.$ and $1.5 \times 10^{4} \pm 0.9$ colony forming units, respectively). Representative spore localization studies are shown in Tables II and III. Blood, lung, and brain of diabetic mice were heavily seeded following intranasal inoculation with $10^{6}$ 
Table I. Blood Values* in Normal and Streptozotocin-treated Mice with or without Intranasal Challenge by Rhizopus oryzae

\begin{tabular}{lllll}
\hline Mice & Blood pH & Glucose & $\beta$-Hydroxybutyrate & Acetoacetate \\
\hline $\begin{array}{c}\text { Controlł } \\
\text { unchallenged }\end{array}$ & $7.8( \pm 0)$ & $103( \pm 3)$ & $0.08( \pm 0.02)$ & $0.03( \pm 0.01)$ \\
$\begin{array}{c}7 \text { d after STZ } \\
\text { unchallenged }\end{array}$ & $7.3( \pm 0.06)$ & $269( \pm 14)$ & $0.32( \pm 0.04)$ & $0.07( \pm 0.05)$ \\
$\begin{array}{c}10 \text { d after STZ } \\
\text { unchallenged }\end{array}$ & $7.3( \pm 0.06)$ & $256( \pm 5)$ & $0.67( \pm 0.07)$ & $0.06( \pm 0.03)$ \\
$\begin{array}{c}\text { Control } \\
\text { challenged }\end{array}$ & $7.4( \pm 0.06)$ & $129( \pm 14)$ & $0.04( \pm 0.03)$ & $0.03( \pm 0.02)$ \\
$\begin{array}{c}10 \text { d after STZ } \\
\text { challenged }\end{array}$ & $7.2( \pm 0)$ & $225( \pm 8)$ & $0.19( \pm 0.17)$ & $0.07( \pm 0.01)$
\end{tabular}

STZ, streptozotocin.

* Mean $( \pm S D)$ from three pools of sera; each pool from three to five nonfasted mice.

$\ddagger 0.2 \mathrm{ml}$ citrate buffer intraperitoneally.

$\S 250 \mathrm{mg} / \mathrm{kg}$ streptozotocin in $0.2 \mathrm{ml}$ citrate buffer intraperitoneally.

" $10^{6}$ colony forming units $R$. oryzae intranasally. Animals sacrificed $3 \mathrm{~d}$ after challenge.

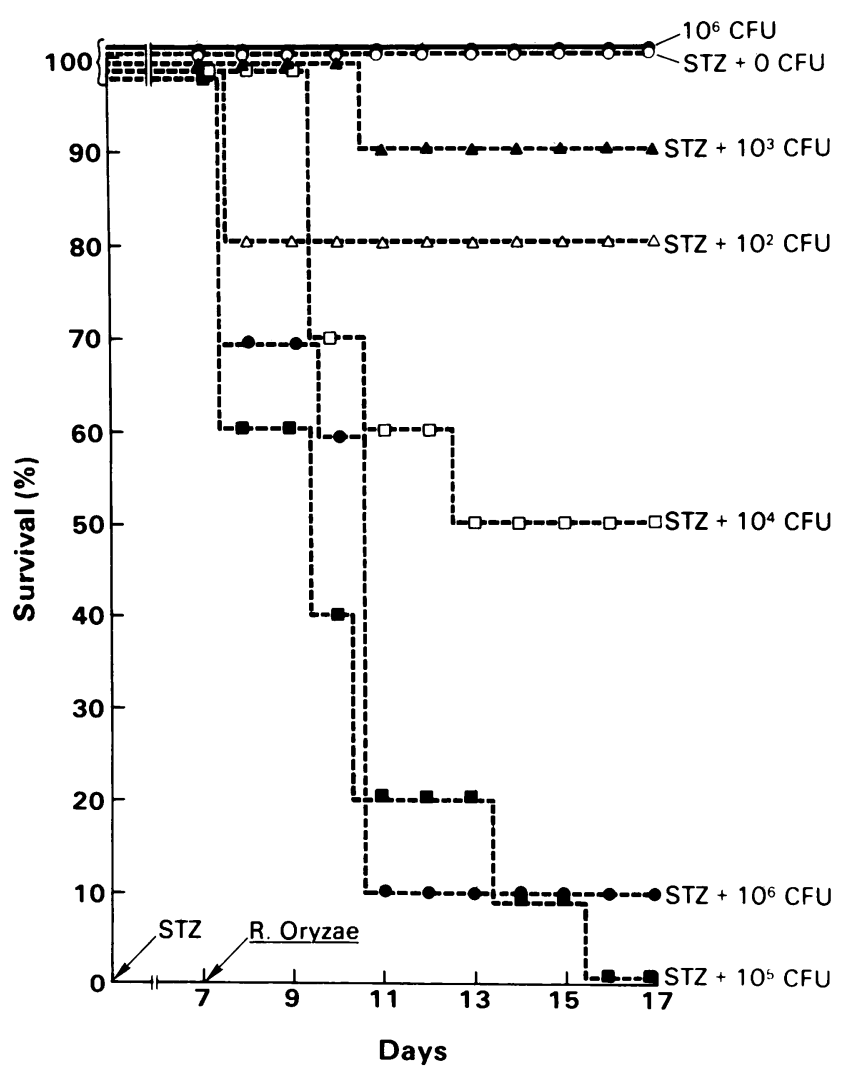

Figure 1. Survival of normal (-) and diabetic (- - ) mice following intranasal challenge with $R$. oryzae. Streptozotocin (STZ, 250 $\mathrm{mg} / \mathrm{kg}$ ) was administered on day $1, R$. oryzae on day 7. $n=20$ at each dosage.
Table II. Rhizopus oryzae Spore Localization* in Diabetic Mice Surviving after Challenge

\begin{tabular}{lcrcccc}
\hline $\begin{array}{l}\text { Days post- } \\
\text { inoculation }\end{array}$ & Blood & Lung & Brain & Spleen & Kidney & Liver \\
\hline 1 & $9 / 10 \S$ & $10 / 10$ & $7 / 10$ & $5 / 10$ & $4 / 10$ & $7 / 10$ \\
2 & $5 / 10$ & $8 / 10$ & $6 / 10$ & $3 / 10$ & $2 / 10$ & $4 / 10$ \\
3 & $3 / 10$ & $10 / 10$ & $4 / 10$ & $4 / 10$ & $3 / 10$ & $3 / 10$ \\
5 & $2 / 10$ & $9 / 10$ & $1 / 10$ & $0 / 10$ & $0 / 10$ & $1 / 10$ \\
7 & $2 / 10$ & $9 / 10$ & $1 / 10$ & $0 / 10$ & $1 / 10$ & $1 / 10$ \\
10 & $1 / 10$ & $10 / 10$ & $0 / 10$ & $0 / 10$ & $1 / 10$ & $0 / 10$ \\
& & & & & &
\end{tabular}

* Following intranasal inoculation with $1 \times 10^{6}$ colony forming units. $\ddagger 75 \%$ mortality with this inoculum: deaths beginning at day 2 . After day 2 . groups of 10 surviving mice were sacrificed.

$\S$ No. of culture positive animals/total.

$R$. oryzae, a $75 \%$ lethal dose (Table II). Even mice surviving challenge with this inoculum did not rapidly clear viable $R$. oryzae from blood and brain tissue. $R$. oryzae could be cultured from normal mouse lung tissue as late as $10 \mathrm{~d}$ after inoculation (Table III). However, viable organisms were cleared rapidly from brain, blood, and kidneys, so that cultures became negative within 2-7 d after inoculation. Pulmonary lesions in the diabetic mice contained irregularly branching hyphal filaments with hyphal invasion of blood vessels. Massive hemorrhage and necrosis surrounding hyphal filaments were observed (Fig. 2). In tissues of normal mice, neither spore germination nor growth occurred, so no hyphal fragments were observed, although spores remained viable. Spores in tissues were surrounded by foci of inflammation, with an influx of mononuclear and polymorphonuclear cells into alveoli.

Infections by A. fumigatus in diabetic mice. A. fumigatus causes histopathologic changes which are similar to those seen in mucormycosis, but unlike the latter, is not associated with diabetes. To determine whether induction of diabetes had created a specific predisposition to mucormycosis rather than a generalized susceptibility to opportunistic mycoses, mice were chal-

Table III. Rhizopus oryzae Spore Localization* in Normal Mice

\begin{tabular}{llrllll}
$\begin{array}{l}\text { Days post- } \\
\text { inoculation }\end{array}$ & Blood & Lung & Brain & Spleen & Kidney & Liver \\
\hline 1 & $1 / 10 \S$ & $9 / 10$ & $3 / 10$ & $3 / 10$ & $3 / 10$ & $4 / 10$ \\
2 & $1 / 10$ & $9 / 10$ & $0 / 10$ & $5 / 10$ & $2 / 10$ & $4 / 10$ \\
3 & $2 / 10$ & $10 / 10$ & $0 / 10$ & $3 / 10$ & $2 / 10$ & $4 / 10$ \\
5 & $0 / 10$ & $10 / 10$ & $0 / 10$ & $6 / 10$ & $3 / 10$ & $3 / 10$ \\
7 & $0 / 10$ & $7 / 10$ & $0 / 10$ & $0 / 10$ & $0 / 10$ & $2 / 10$ \\
10 & $0 / 10$ & $10 / 10$ & $0 / 10$ & $2 / 10$ & $0 / 10$ & $3 / 10$
\end{tabular}

* Following intranasal inoculation with $1 \times 10^{6}$ colony forming units. $\ddagger 0 \%$ mortality with this inoculum.

$\S$ No. of culture positive animals/total. 


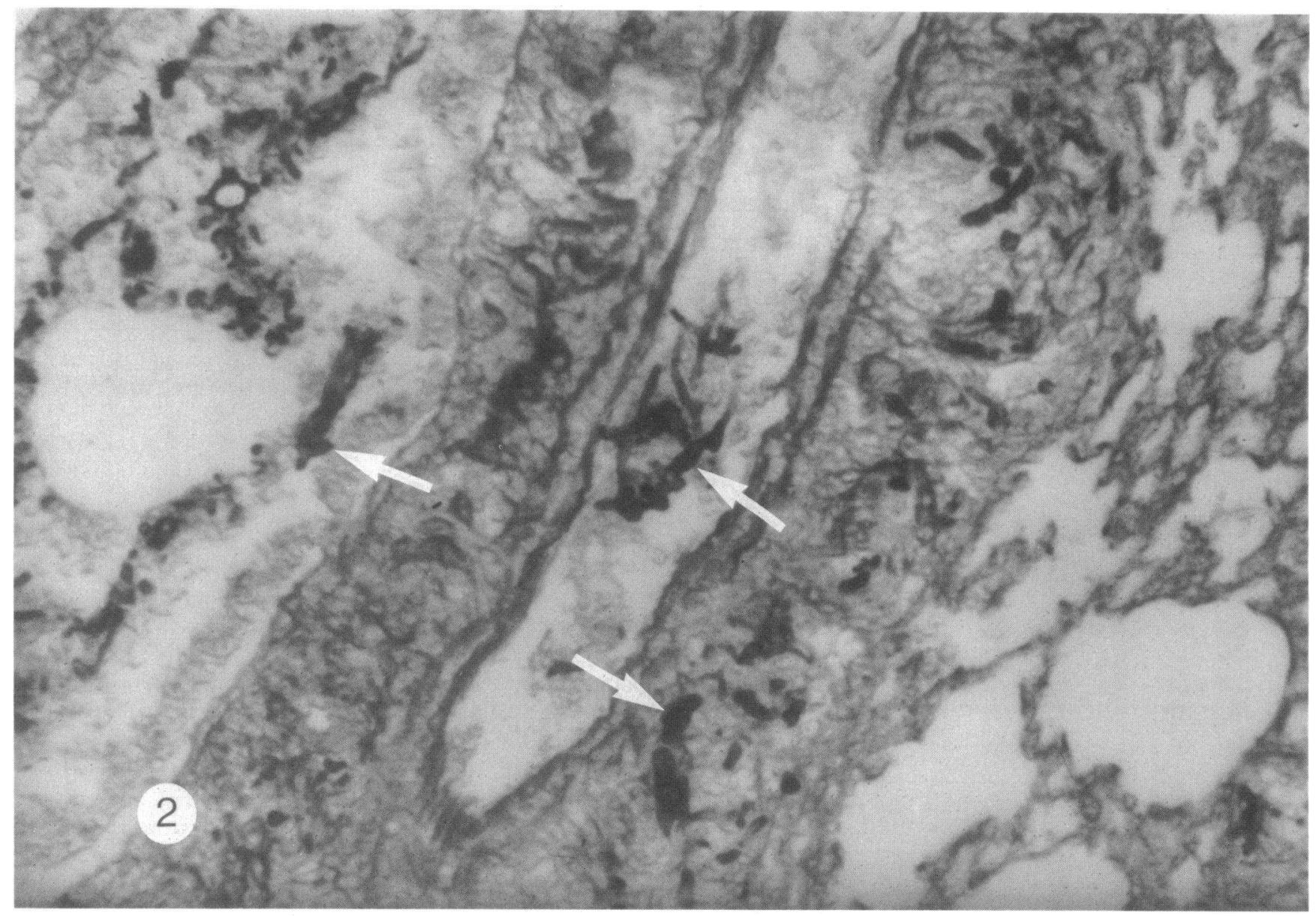

Figure 2. Lung lesion from diabetic mouse $4 \mathrm{~d}$ after inoculation with $10^{6} R$. oryzae spores. Grocott methenamine silver-positive fungal hy-

lenged with this organism. The survival of normal and diabetic mice following intranasal challenge with $10^{6} R$. oryzae or $A$. fumigatus is shown in Fig. 3. When diabetic mice were challenged with $A$. fumigatus, there were significantly fewer fatal infections $(P=0.018$, rank sum) than diabetic mice challenged with $R$. oryzae. However, lung recovery experiments indicated that a higher inocula of $A$. fumigatus $\left(8.4 \times 10^{5} \pm 1.0\right)$ reaches the lung than does $R$. oryzae $\left(1.7 \times 10^{4} \pm 1.9, P<0.001, t\right.$ test $)$ after intranasal inoculation with $10^{6}$ conidia or spores. There was no mortality in normal mice inoculated with $3 \times 10^{6} \mathrm{~A}$. fumigatus.

Germination of $R$. oryzae in vivo. Bronchoalveolar lavage was performed on normal and diabetic mice at $18 \mathrm{~h}$ after intranasal inoculation of spores. The percent of spores ingested by or attached to bronchoalveolar macrophages and percent spore germination were then determined. The same total number of lavaged leukocytes was obtained from normal and diabetic mice $\left(3.6 \times 10^{6} \pm 1.0\right.$ and $3.6 \times 10^{6} \pm 3.0 /$ mouse, respectively). There were no differences between normal and diabetic cells in the mean number of spores attached to or ingested by mac- phae (arrow) in bronchiole and blood vessel. Grocott methenamine silver stain with light green counter stain $(\times 100)$.

rophages when counted immediately after lavage or following centrifugation and washings (Table IV). However, following subsequent in vitro incubation, there were fewer diabetic macrophages remaining associated with $R$. oryzae spores $(P<0.001)$. Results of giemsa, nonspecific esterase (34), and acridine orange (35) staining confirmed that decreased attachment to spores was not attributable to lower numbers of bronchoalveolar macrophages in lavage fluid from diabetic than from normal mice $(87.7 \pm 3.0$ and $87.3 \pm 2.9 \%$, respectively). Moreover, diabetic and normal cell viability remained comparable through the $5-\mathrm{h}$ incubation. Germination of $R$. oryzae spores was observed only in lavage fluids from diabetic mice $(P<0.01)$ (Table IV). After $3 \mathrm{~h}$ of subsequent in vitro incubation, the germination rate of lavaged spores increased only in samples from the diabetic mice $(P<0.001)$. Germination of spores occurred in the diabetic lavage fluids irrespective of their association with macrophages at the time of observation.

Attachment and bronchoalveolar macrophage-mediated damage to spores and hyphae in vitro. The above in vivo ex- 
Table IV. Percent of Spores with Alveolar Lavage Cells Associated and Percent Spore Germination following In Vivo Incubation*

\begin{tabular}{|c|c|c|c|c|c|}
\hline & \multicolumn{3}{|c|}{ Percent spores with cells associated } & \multicolumn{2}{|c|}{ Percent spore germination } \\
\hline & $0 \mathrm{~h} \ddagger$ & $3 \mathrm{~h}$ & $5 \mathrm{~h}$ & $\mathbf{O h}$ & $3 \mathrm{~h}$ \\
\hline Normal mice & $67.0( \pm 15.3)$ & $78.0( \pm 21.0)$ & $61.6( \pm 16.2)$ & $0.10( \pm 0.01)$ & $2.0( \pm 0.7)$ \\
\hline Diabetic mice & $56.3( \pm 9.1)$ & $42.7( \pm 6.5) \S$ & $35.3( \pm 4.3) \S$ & $10.3( \pm 5.73) \S$ & $44.3( \pm 9.5) \S$ \\
\hline
\end{tabular}

* Mean $( \pm \mathrm{SEM})$ of three experiments using a pool of lavaged alveolar cells and spores from three to five mice $18 \mathrm{~h}$ after intranasal inoculation. $\ddagger$ Hours after lavage, of in vitro shaking incubation at $37^{\circ} \mathrm{C}, 5 \% \mathrm{CO}_{2} . \S P \leq 0.01, t$ test, comparing diabetic with normal at the respective time.

periments served to document events which occurred relatively late after challenge (i.e., after $18 \mathrm{~h}$ ) and in the presence of bronchoalveolar lavage fluid rather than the circulation. Therefore, in vitro studies were performed which permitted simultaneous quantitative assessment of multiple variables in order to investigate the sequence of events occurring at earlier time periods, while directly comparing serum-mediated effects with those of alveolar-lining material in macrophage-fungus interactions. The effects of sera and alveolar-lining material on the ability of normal

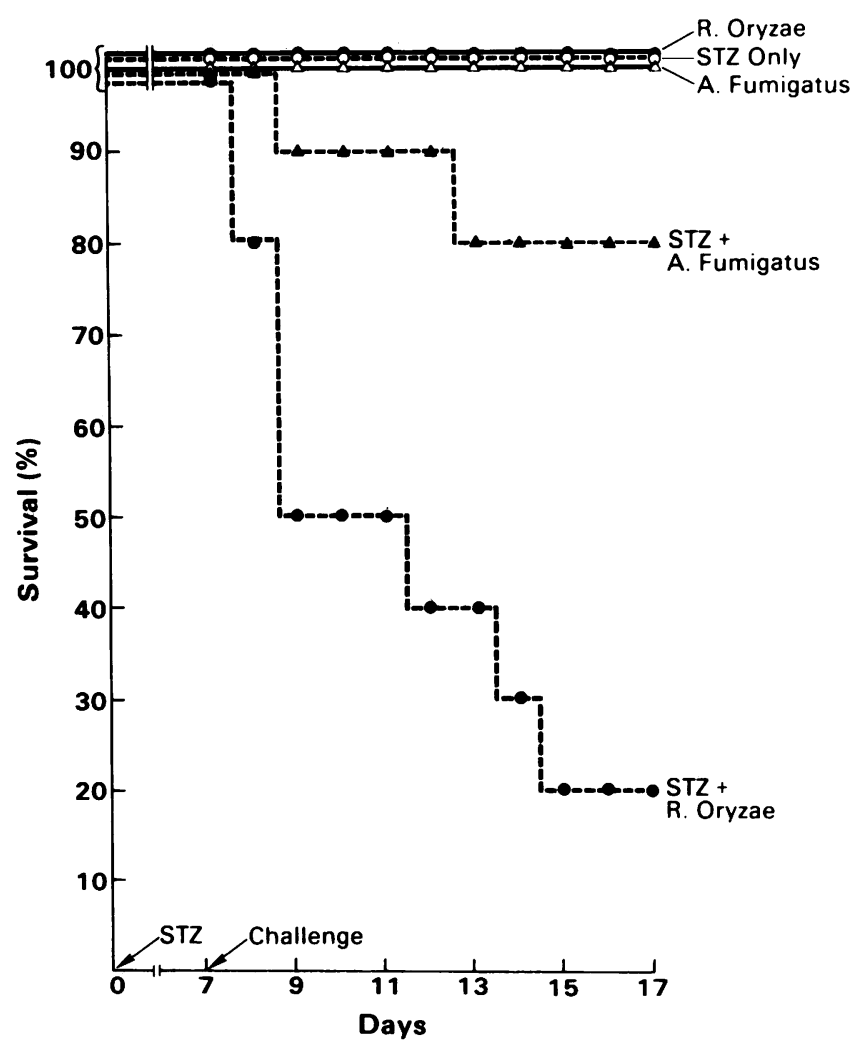

Figure 3. Survival of normal (-) and diabetic (- -$)$ mice following intranasal challenge of $R$. oryzae $\left(1 \times 10^{6}\right.$ colony forming units) $(\bullet)$ or $\dot{A}$. fumigatus $\left(1 \times 10^{6}\right.$ colony forming units) ( $)$. Streptozotocin (STZ, $250 \mathrm{mg} / \mathrm{kg}$ ) was administered on day 1 , fungi on day 7. $n$ $=20$ at each dosage. or diabetic bronchoalveolar macrophages from uninoculated mice to attach in vitro to $R$. oryzae spores and hyphae are summarized in Table V. Diabetic sera, in comparison to normal sera, reduced the ability of normal and diabetic macrophages to attach to $R$. oryzae spores $(P<0.003)$. Attachment of cells to spores was unaffected by incubation of alveolar-lining material in place of buffer. There was no difference in attachment to spores between normal and diabetic cells.

In contrast to spores, there was no effect of diabetic sera on attachment of normal macrophages to hyphae. However, the number of diabetic macrophages attached to $R$. oryzae hyphae was decreased when compared with normal cells $(P<0.001)$ (Table V).

Evidence for the importance of bronchoalveolar macrophages as a potential defense against $R$. oryzae spores was obtained from studies on the interaction of these cells with $R$. oryzae spores. In three separate experiments, diabetic bron-

Table V. Association of Alveolar Macrophages with $R$. oryzae Spores and Hyphae*

\begin{tabular}{|c|c|c|}
\hline Diluent & Normal cells & Diabetic cells \\
\hline & \multicolumn{2}{|c|}{ Percent associated with spores } \\
\hline HBSS & $46.3( \pm 12.8)$ & $42.5( \pm 14.2)$ \\
\hline Normal serał & $70.3( \pm 2.67)$ & $58.5( \pm 6.6)$ \\
\hline Diabetic serał & $25.0( \pm 1.73)^{\prime \prime}$ & $32.5( \pm 5.3)^{\prime \prime}$ \\
\hline Normal ALM§ & $37.0( \pm 12.1)$ & $38.0 \quad( \pm 4.0)$ \\
\hline \multirow[t]{2}{*}{ Diabetic ALM§ } & $49.0( \pm 11.7)$ & $28.33( \pm 5.5)$ \\
\hline & \multicolumn{2}{|c|}{ Percent associated with hyphae } \\
\hline HBSS & $45.0( \pm 10.8)$ & $19.0( \pm 7.2)^{* *}$ \\
\hline Normal serał & $50.0( \pm 14.7)$ & $26.33( \pm 9.7)^{* *}$ \\
\hline Diabetic serał & $76.7( \pm 0.3)$ & $14.0( \pm 7.6)^{* *}$ \\
\hline
\end{tabular}

* Mean ( \pm SEM) of at least three experiments counting 100 fungi. $\ddagger 50 \%$ (vol/vol) fresh sera.

$\S$ ALM, alveolar-lining material, $50 \%$ (vol/vol).

" $P<0.003$, factorial analysis of variance and Scheffe comparison between normal and diabetic sera.

** $P<0.001$, factorial analysis of variance. Difference between normal and diabetic cells. 
Table VI. Alveolar Macrophage-mediated Percent Reduction in $R$. oryzae Spore Germination*

\begin{tabular}{lll}
\hline Diluent & Normal cells & Diabetic cells \\
\hline HBSS-PS $\ddagger$ & $34.3( \pm 4.3)$ & $2.5( \pm 1.41)^{\prime \prime}$ \\
Normal sera & $28.8( \pm 7.78)$ & $1.8( \pm 0.35)^{\prime \prime}$ \\
Diabetic sera & $24.2( \pm 4.45)$ & $0.9( \pm 0.85)^{\prime \prime}$
\end{tabular}

* Mean $( \pm$ SEM) of three experiments run in replicates of 10 . $\ddagger$ HBSS-PS, HBSS with penicillin and streptomycin. $\S 50 \%$ (vol/vol) fresh sera.

" $P<0.001$, factorial analysis of variance. Difference between normal and diabetic cells.

choalveolar macrophages were less effective than normals in inhibiting germination of $R$. oryzae spores in vitro $(P<0.001)$ (Table VI). There was no effect of sera on inhibition of ger- mination. Determination of germination rates was precluded beyond $15 \mathrm{~h}$ because of progressive growth of hyphae.

Damage to spores and hyphae, measured by a reduction in $\left[{ }^{14} \mathrm{C}\right]$ uracil incorporation by fungi, following incubation with bronchoalveolar macrophages in buffer or sera was then determined. Normal and diabetic macrophages damaged $R$. oryzae spores $(35.2 \pm 4.77$ and $52.8 \pm 16.51 \%$ reduction in isotope incorporation, respectively) and hyphae $(59.33 \pm 27.82$ and $40.87 \pm 18.59 \%$, respectively). Incubation in $50 \%$ (vol/vol) fresh normal or diabetic sera did not affect the results.

Respiratory burst activity. Chemiluminescence and superoxide assays were performed on normal and diabetic bronchoalveolar macrophages to estimate their ability to undergo a respiratory burst. Luminol-enhanced chemiluminescence with normal and diabetic bronchoalveolar macrophages was examined. Opsonized zymosan and opsonized $R$. oryzae spores generated chemiluminescence from normal and diabetic alveolar macrophages in a concentration-dependent manner. The average

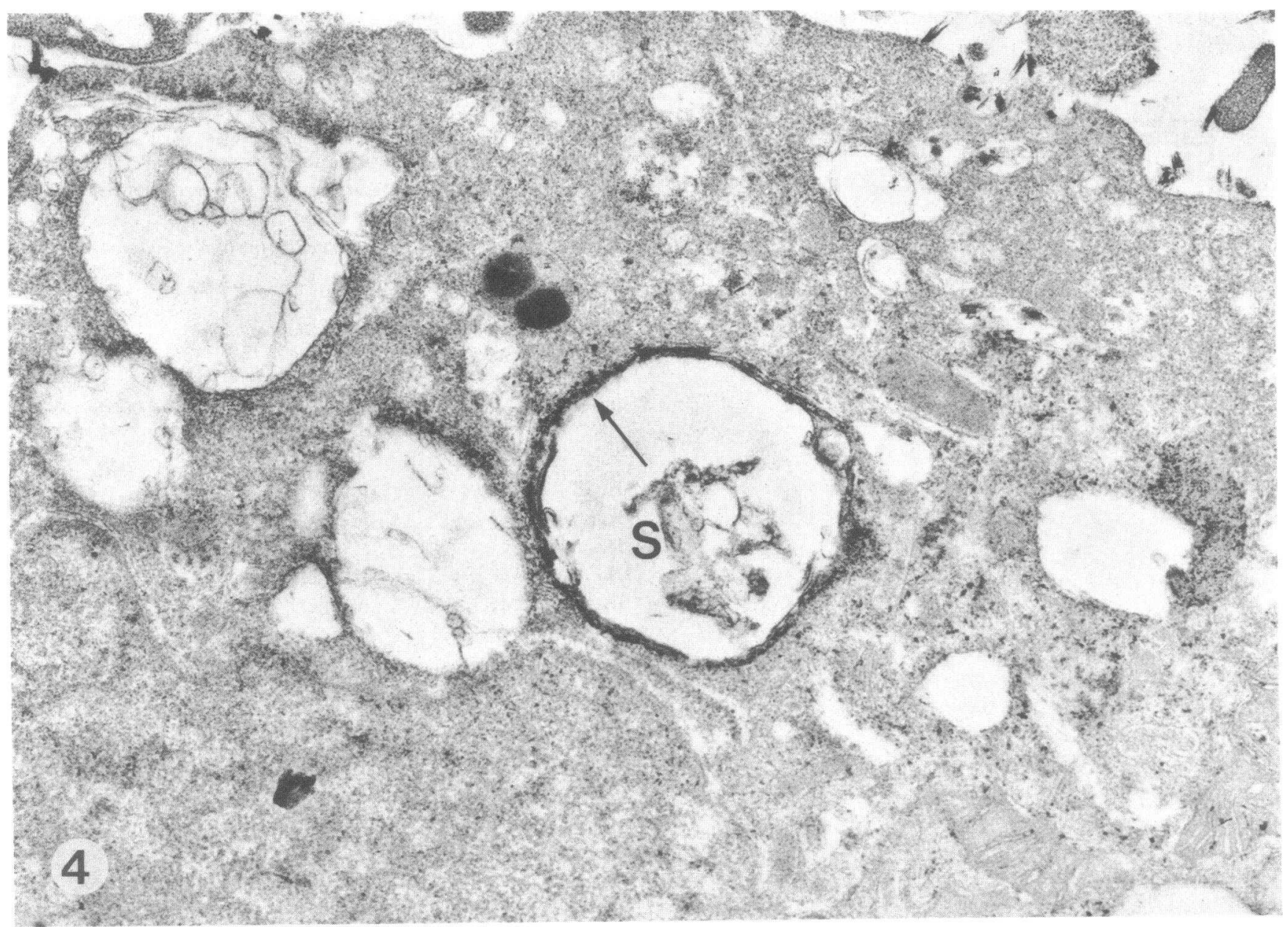

Figure 4. Acid phosphatase activity (arrow) (cytidine monophosphate, pH 5.0, $1 \mathrm{~h}, 45 \mathrm{~min}$ ) within a large phagosome in a diabetic bron- choalveolar macrophage containing remnents of $R$. oryzae spore (S) $(\times 33,000)$. 
peak response occurred at $0.62 \pm 0.2 \mathrm{~min}$ in five experiments using different cell populations. There was no significant difference between normal and diabetic macrophage chemiluminescence $\left(7.2 \times 10^{-3} \mathrm{cpm}\right.$ representative peak and $16.5 \times 10^{-3}$ cpm representative peak, respectively).

Normal and diabetic bronchoalveolar macrophages were compared for their phorbol myristate acetate-induced superoxide production. There was no significant difference in the mean initial rate of superoxide-dependent ferricytochrome $\mathrm{C}$ reduction in normal and diabetic macrophages $(0.67 \pm 0.19$ and $0.18 \pm 0.04$ $\mathrm{nmol} / \mathrm{min} / 10^{6}$ cells, respectively).

Phagosome-lysosome fusion. Cytidilic acid was used to label acid phosphatase in lysosomes in order to study their fusion potential in normal and diabetic bronchoalveolar macrophages following phagocytosis of spores. Various degrees of labeled lysosomes with phagosomes are shown in Fig. 4. The presence of the acid phosphatase marker in the phagosomes as shown
(Fig. 5) is indicative of lysosome-phagosome fusion. There was no defect in fusion in the diabetic macrophages.

Direct effects of sera on germination of $R$. oryzae in vitro. With increasing concentrations of sera $>35 \%$, normal mouse sera allowed germination of $<50 \%$ of $R$. oryzae spores, whereas spore germination progressively increased in diabetic mouse sera (Fig. 6). Differences in percent germination were significant $(P \leq 0.01)$ at serum concentrations of $\geq 50 \%$. Germination assays in the presence of varying combinations of normal and diabetic sera indicated that normal sera did not inhibit germination, rather diabetic sera promoted spore germination (data not shown).

Because available iron can affect $R$. oryzae growth, the mean serum iron and total iron-binding capacity from three pools of normal and diabetic mouse sera were determined (Table VII). There were no significant differences in serum iron nor total iron-binding capacity between normal or diabetic mice. The

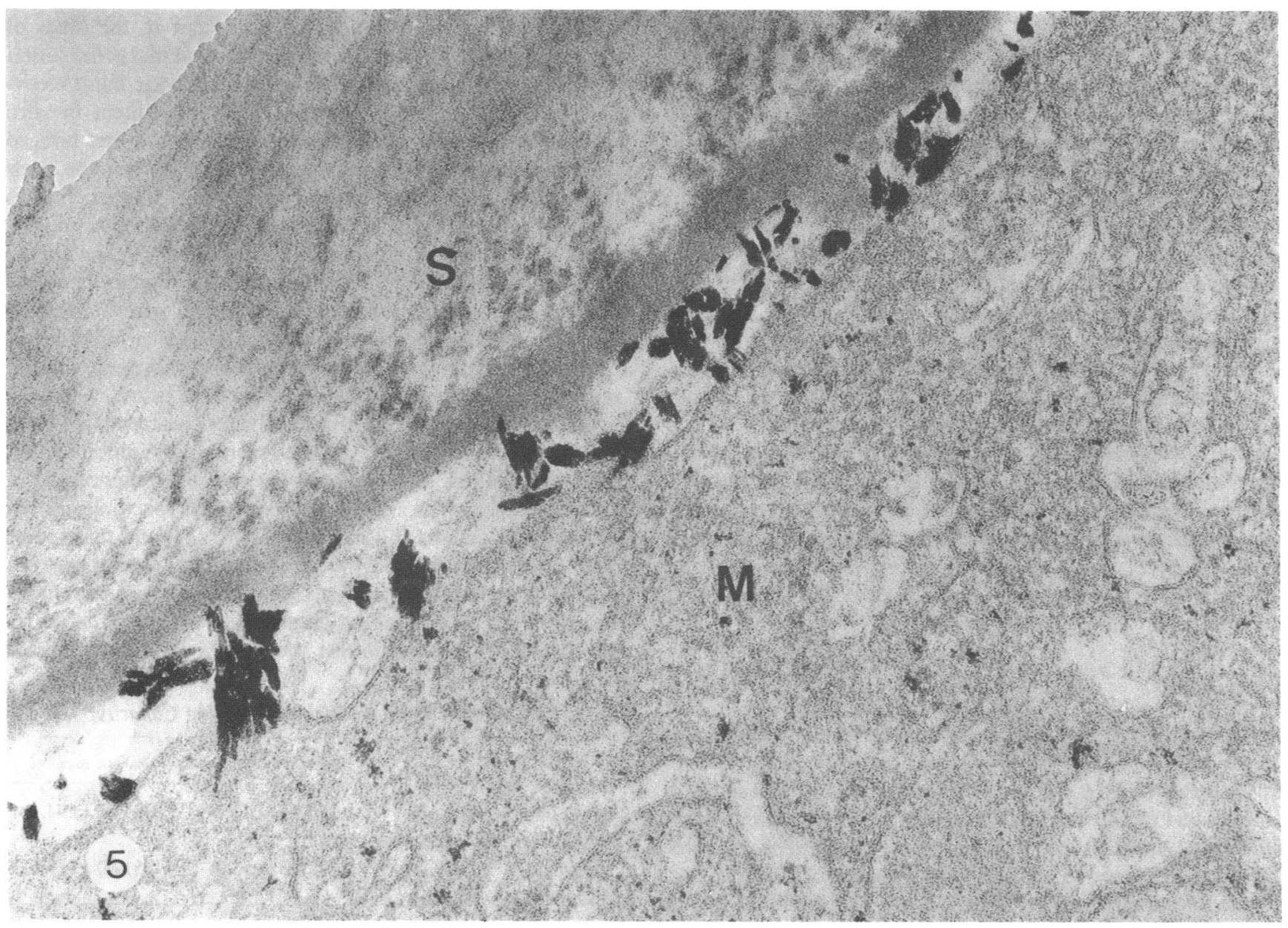

Figure 5. Acid phosphatese activity (arrow) (cytidine monophosphate, pH 5.0, $1 \mathrm{~h}, 45 \mathrm{~min}$ ) within a large phagosome in a diabetic bron- choalveolar macrophage (M) containing a $R$. oryzae spore (S) $(\times 125,500)$. 


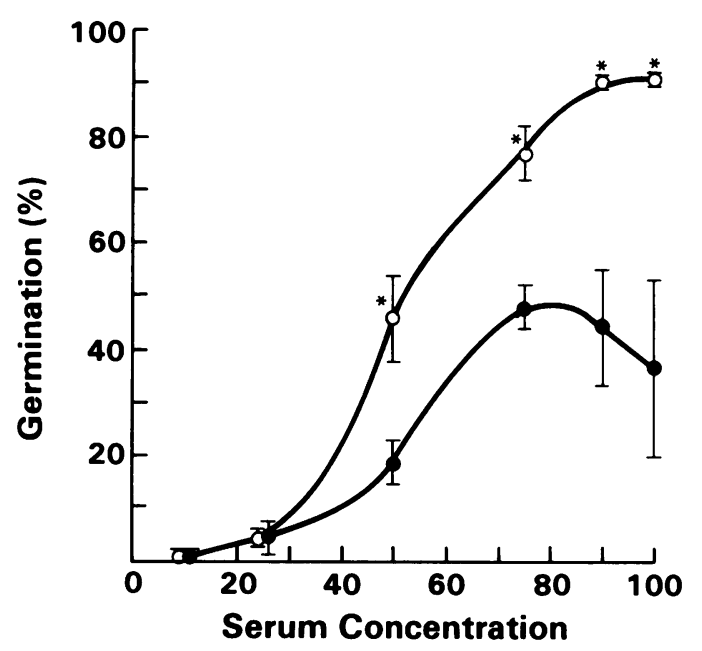

Figure 6. Effects of serum concentration of $R$. oryzae spore germination in vitro. Normal $(\bullet)$ or diabetic $(0)$ sera diluted in bicarbonate buffer. Mean \pm SEM of three separate experiments run in triplicate. *, $P<0.01, t$ test.

percent germination of $R$. oryzae in normal and diabetic sera could not be altered with the addition of iron concentrations that exceeded complete saturation of the total iron-binding capacity $(87.33 \mu \mathrm{g} / \mathrm{dl})$, nor with the addition of sufficient transferrin to bind all free serum iron $(35.33 \mu \mathrm{g} / \mathrm{dl})$ (data not shown).

The addition of insulin or complement to buffered sera in physiologic or supraphysiologic concentrations did not alter the glucose concentration, the $\mathrm{pH}$ of the suspensions, nor the percent spore germination. There was no lysis of $R$. oryzae spores in sera with or without complement addition, and spores were viable when subsequently inoculated into Sabouraud's broth.

Comparable $R$. oryzae spore germination occurred in both normal and diabetic alveolar-lining material (47.25 \pm 2.06 and $51.50 \pm 1.07$, respectively), although normal alveolar-lining material had significantly higher glucose concentrations than diabetic $(115 \pm 3.5$ and $35.5 \pm 2.5 \mathrm{mg} / \mathrm{dl}, P<0.001)$. Both normal and diabetic alveolar-lining material were approximately neutral (pH, 7.32 \pm 0.27 and 6.95 \pm 0.03 , respectively). There was no measurable free iron in either normal or diabetic alveolar-lining material.

\section{Discussion}

In these studies, streptozotocin induced a mild ketoacidotic diabetes in mice that were predisposed to pulmonary mucormycosis caused by $R$. oryzae. Our results confirm that diabetic animals had rapidly fatal infection with $R$. oryzae, Rhizomucor pusillus, $R$. arrhizus (4), $R$. microsporus (4), Rhizopodiformis (4), or Absidia corymbifera (5). Intranasal inoculation of $R$. oryzae into diabetic mice resulted in mucormycotic infections which presented pathology closely resembling pulmonary mucormycosis observed in humans: extensive tissue necrosis in the vicinity of hyphae and the penetration of hyphae into vascular structures.

The animal models which have been used previously to examine lowered resistance to mucormycosis have questionable relevance to human mucormycotic infection because of the nonspecificity of effects of inducing agents on host immunity (6-12). Sidransky and Verney (11) used alloxan-induced diabetes to predispose mice and found $50-80 \%$ mortality following intranasal inoculation with $A$. flavus. In contrast, streptozotocininduced diabetic mice utilized in the present study developed severe $R$. oryzae infections after challenge intranasally to induce infections by the natural (respiratory) route; yet, they were far less susceptible to challenge with $A$. fumigatus. These findings parallel the specific enhanced susceptibility to mucormycosis observed in human diabetics. Thus, for the first time, this model provides the opportunity to investigate specific features of host immunologic and natural defense systems that relate to a specific opportunistic mycotic infection.

The observation that spore germination occurred only in diabetic mice following intranasal inoculation confirms earlier studies in which germination did not occur in the lungs of normal mice $(12,13,36)$. Moreover, we found that germination of spores occurred only in bronchoalveolar lavage fluids recovered from diabetic mice. However, with subsequent in vitro incubation in media which favors germination, spores lavaged from diabetic and normal mice germinated at comparable levels $(68.3 \pm 2.7$ and $64.4 \pm 1.5$, respectively). Thus, $R$. oryzae spores were not easily killed by either normal or diabetic mice in spite of normal oxidative killing mechanisms, which may explain the recovery of viable spores from the lungs of normal mice as late as $10 \mathrm{~d}$ after inoculation. That these spores germinated and grew in vitro suggests that the absence of hyphal forms in inoculated normal mice is due to inhibition of spore germination rather than destruction of the spores in lung tissue.

It appears that normal bronchoalveolar macrophages form part of an efficient defense against $R$. oryzae by inhibiting germination, the first step necessary for control of these fungi in vivo. Consistent with reports that peritoneal macrophages kill $A$. fumigatus conidia in vivo and in vitro (28) and that spores of $R$. arrhizus are phagocytized by pulmonary macrophages in vitro (37), we found that normal bronchoalveolar macrophages attach to, ingest, and inhibit germination of $R$. oryzae spores in vivo and in vitro. In contrast, there was a significant decrease

Table VII. Serum Iron and Total Iron-binding Capacity*

\begin{tabular}{lll}
\hline & Normal mice & Diabetic mice \\
\hline $\begin{array}{l}\text { Serum iron }(\mu g / d l) \\
\begin{array}{l}\text { Total iron-binding capacity } \\
(\mu g / d l)\end{array}\end{array}$ & $310.67( \pm 11.29)$ & $386.33( \pm 94.18)$ \\
& $398.00( \pm 5.29)$ & $351.00( \pm 19.67)$
\end{tabular}

* Mean $( \pm$ SEM) from three pools of sera; each pool from three to five mice. 
in inhibition of spore germination by diabetic bronchoalveolar macrophages in vivo and in vitro. This decrease was not attributable to defects in respiratory burst activity nor phagosomelysosome fusion of bronchoalveolar macrophages.

Beyond effects on germination, we have extended our previous results of leukocyte-mediated damage $(16,17)$ to include the effects of bronchoalveolar macrophage-mediated damage to $R$. oryzae spores and hyphae. Normal macrophages attached to and damaged $R$. oryzae spores as measured by both reduced isotope incorporation and reduction in plate counts. Additionally, normal mouse macrophages damaged the large tissue-invasive hyphae of $R$. oryzae in the absence of complete ingestion. The mean amount and range of damage to hyphae by bronchoalveolar macrophages from normal mice were consistent with that observed in prior studies with polymorphonuclear and mononuclear cells $(16,17)$. With all cell types, attachment to hyphae occurred in the absence of serum. Experiments performed with diabetic bronchoalveolar macrophages and diabetic sera resulted in a similar range of macrophage-mediated damage.

A decreased affinity of diabetic bronchoalveolar macrophages for $R$. oryzae spores following lavage and subsequent in vitro incubation was observed. Diabetic sera also reduced the attachment of normal and diabetic macrophages to spores. These in vitro results contrast with those noted above in vivo, where differences in attachment of macrophages to fungi were not observed. However, this is not surprising for two reasons: first, because the in vivo results reflect a prolonged $(18 \mathrm{~h})$ incubation period where early defects in cell contact might be overcome and, second, because the in vivo studies presumably reflect primarily the opsonic effects of bronchoalveolar lavage fluid rather than of sera. Thus, the diabetic milieu in serum may limit the effectiveness of macrophages in clearance of fungi from the bronchoalveolar spaces and from the pulmonary circulation; ultimately, this may then determine whether or not initial infections progress. This is particularly relevant because, as noted above, viable spores disseminate even in normal mice, but germination and progression of mucormycosis occurred only in diabetic animals. Within the bronchoalveolar spaces, alveolarlining material may play a major role in antimicrobial defenses $(27,38,39)$. However, in vitro germination assays using alveolarlining material from normal and diabetic mice indicated that, unlike the reported bactericidal effects $(27,38,39)$, alveolarlining material had no fungicidal activity. Additionally, there was neither increased attachment nor enhanced bronchoalveolar macrophage-mediated fungicidal activity against spores in the presence of alveolar-lining material. Thus, results of our in vitro and in vivo studies may reflect differences in localization and/ or time course of diabetic-associated defects in macrophage antifungal activity.

Normal human serum inhibits the hyphal growth of zygomycete species (40), and this inhibitory activity is reduced in serum from ketoacidotic diabetic patients (41). We have previously shown that the factor(s) which restrict spore germination are reversible and are not antispore antibodies (13). Our findings of limited spore germination in normal mouse sera and increasing spore germination in diabetic sera extend these observations to the critical step involving conversion of $R$. oryzae to its tissue-invasive growth phase. Hyperglycemia alone does not permit spore germination, as addition of $\geq 300 \mathrm{mg} / \mathrm{dl}$ glucose to normal mouse sera did not increase spore germination (Waldorf and Diamond, unpublished data). Moreover, rabbits rendered hyperglycemic (but not ketoacidotic) by sustained glucose infusions or chronic alloxan-diabetes were not susceptible to infection by intranasal inoculation $(5,42)$. It has been postulated that at the normal human blood $\mathrm{pH}$, iron is chelated by transferrin, leaving little or no free iron in the sera to support fungal growth (3). However, neither excess iron nor transferrin altered spore germination in normal or diabetic sera. Because normal mouse blood $\mathrm{pH}$ is alkaline ( $\mathrm{pH}$ 7.8) and dropped to a mildly acidotic $\mathrm{pH}$ (7.4) after intranasal challenge of normal mice without causing infection, it appears that $\mathrm{pH}$ effects on iron availability is only one of several components which might affect germination.

Specific host defense defects accounting for the enhanced susceptibility of uncontrolled diabetics to mucormycosis are not well characterized. The streptozotocin-induced murine model of diabetes provides a system for examination of host immune factors affecting the pathogenesis of mucormycosis. Prevention of mucormycosis requires control of either spore germination and/or hyphal growth by the host. The predisposing factors in murine diabetes to mucormycosis appear to be multifactorial. We found that in diabetic mice, bronchoalveolar macrophages had a decreased ability to inhibit germination of $R$. oryzae spores, and serum factors appeared to both promote germination and impair attachment of macrophages to spores.

\section{Acknowledgments}

This work was supported by U. S. Public Health Service grant AI15338 from the National Institute of Allergy and Infectious Diseases and by Training Grant HL07501 from the National Heart, Lung and Blood Institute of National Institutes of Health.

\section{References}

1. Hart, P. D., E. Russel, Jr., and J. S. Remington. 1969. The compromised host and infection. II. Deep fungal infection. J. Infect. Dis. 120:169-191.

2. Marchevsky, A. M., E. J. Bottone, S. A. Geller, and D. K. Giger. 1980. The changing spectrum of disease, etiology, and diagnosis of mucormycosis. Hum. Pathol. 11:457-464.

3. Artis, W. M., J. A. Fountain, H. K. Delcher, and H. E. Jones. 1982. A mechanism of susceptibility to mucormycosis in diabetic ketoacidosis: transferrin and iron availability. Diabetes. 31:1109-1114.

4. Reinhardt, D. J., I. Licata, W. Kaplan, L. Ajello, F. W. Chandler, and J. J. Ellis. 1981. Experimental cerebral zygomycosis in alloxandiabetic rabbits: variation in virulence among zygomycetes. Sabouraudia. 19:245-255.

5. Sheldon, W. H., and H. Bauer. 1959. The development of the 
acute inflammatory response to experimental cutaneous mucormycosis in normal and diabetic rabbits. J. Exp. Med. 110:845-852.

6. Baker, R. D., and G. Linares. 1974. Prednisolone-induced mucormycosis in Rhesus monkeys. Sabouraudia. 12:75-80.

7. Corbel, M. J., and S. M. Eades. 1977. Experimental mucormycosis in congenitally athymic (nude) mice. Mycopathologia. 62:117-120.

8. Corbel, M. J., and S. M. Eades. 1976. The relative susceptibility of New Zealand black and CBA mice to infection with opportunistic fungal pathogens. Sabouraudia. 14:17-32.

9. Corbel, M. J., and S. M. Eades. 1975. Factors determining the susceptibility of mice to experimental phycomycosis. J. Med. Microbiol. 8:551-564.

10. Eades, S. M., and M. J. Corbel. 1975. Enhancement of susceptibility to experimental phycomycosis by agents producing reticuloendothelial stimulation. Br. Vet. J. 131:622-624.

11. Sidransky, H., and E. Verney. 1962. Experimental aspergillosis. Lab. Invest. 11:1172-1183.

12. Waldorf, A. R., C. Halde, and N. A. Vedros. 1982. Murine model of pulmonary mucormycosis in cortisone-treated mice. Sabouraudia. 20:217-224.

13. Waldorf, A. R., L. Peter, and A.-M. Polak. 1984. Mucormycotic infection in mice following prolonged in vivo incubation of spores and the role of spore agglutinating antibodies on spore germination. $\mathrm{Sa}$ bouraudia. 22:101-108.

14. Hoidal, J. R., D. Schmeling, and P. K. Peterson. 1981. Phagocytosis, bacterial killing and metabolism by purified human lung phagocytes. J. Infect. Dis. 144:61-71.

15. Diamond, R. D., and R. A. Clark. 1982. Damage to Aspergillus fumigatus and Rhizopus oryzae hyphae by oxidative and nonoxidative microbicidal products of human neutrophils in vitro. Infect. Immun. 38:487-495.

16. Diamond, R. D., C. C. Haudenschild, and N. F. Erickson III. 1982. Monocyte-mediated damage to Rhizopus oryzae hyphae in vitro. Infect. Immun. 38:292-297.

17. Diamond, R. D., R. Krzesicki, B. Epstein, and W. Jao. 1978. Damage to hyphal forms of fungi by human leukocytes in vitro. Am. J. Pathol. 91:313-323.

18. Agarwal, M. K. 1980. Streptozotocin: mechanisms of action. FEBS Lett. 120:1-3.

19. Reed, L. J., and H. Muench. 1938. A simple and reliable method of estimating 50\% end points. Am. J. Hyg. 27:493-497.

20. Holt, P. G. 1979. Alveolar macrophages. I. A simple technique for preparation of high numbers of viable alveolar macrophages from small laboratory animals. J. Immunol. Methods. 27:189-198.

21. Mickenberg, I. D., R. K. Root, and S. M. Wolff. 1970. Leukocyte function in hypogammaglobulinemia. J. Clin. Invest. 49:1528-1538.

22. Bergermeyer, H. U., E. Bernt, F. Schmidt, and H. Stork. 1974. D-glucose determination. Methods Enzymatic Anal. 3:1186-1232.

23. Williamson, D. H., and J. Mellanby. 1974. 3-Hydroxybuterate. Methods Enzymatic Anal. 4:1836-1837.

24. Mellanby, J., and D. H. Williamson. 1974. Acetoacetate. Methods Enzymatic Anal. 4:1840-1843.

25. Goodwin, J. F., B. Murphy, and M. Guillemette. 1966. Direct measurement of serum iron and binding capacity. Clin. Chem. 12:4754.
26. Persijn, J. P., W. van der Slik, and A. Riethorst. 1971. Determination of serum iron and latent iron binding capacity (LIBC). Clin. Chem. Acta. 35:91.

27. Coonrod, J. D., and K. Yoneda. 1983. Detection and partial characterization of antibacterial factor(s) in alveolar lining material of rats. J. Clin. Invest. 71:129-141.

28. Schaffner, A., H. Douglas, and R. Braude. 1982. Selective protection against conidia by mononuclear and against mycelia by polymorphonuclear phagocytes in resistance to Aspergillus. Observations on these two lines of defense in vivo and in vitro with human and mouse phagocytes. J. Clin. Invest. 69:617-631.

29. DeChatelet, L. R., G. D. Long, P. S. Shirley, D. A. Bass, M. J. Thomas, F. W. Henderson, and M. S. Cohen. 1982. Mechanism of the luminol-dependent chemiluminescence of human neutrophils. $\mathrm{J}$. Immunol. 129:1589-1593.

30. Cohen, H. J., and M. E. Chovaniec. 1978. Superoxide generation by digitonin-stimulated guinea pig granulocytes. J. Clin. Invest. 61:10811087.

31. Sorokin, S. P. 1983. Dynamics of lysosomal elements in pulmonary alveolar macrophages. I. The post-activation lysosomal cycle. Anat. Rec. 206:117-143.

32. Oliver, C. 1980. Cytochemical localization of acid phosphatase and trimetaphosphatase activities in exocrine acinar cells. J. Histochem. Cytochem. 28:78-81.

33. Dixon, W. J., and F. J. Massey, Jr. 1969. Introduction to Statistical Analysis. McGraw-Hill, Inc., New York. 167-184, 264-273.

34. Koski, I. R., D. G. Poplack, and R. M. Blaese. 1976. A nonspecific esterase stain for the identification of monocytes and macrophages. In In vitro Methods in Cell Mediated and Tumor Immunity. B. R. Bloom and J. R. David, editors. Academic Press, Inc., New York. 359-362.

35. Smith, D. L., and F. Rommel. 1977. A rapid micromethod for the simultaneous determination of phagocytes-microbicidal activity of human peripheral leukocytes in vitro. J. Immunol. Methods. 17:241247.

36. Smith, J. M. 1976. In vivo development of spores of Absidia ramosa. Sabouraudia. 14:11-15.

37. Lundborg, M., and B. Holma. 1972. In vitro phagocytosis of fungal spores by rabbit lung macrophages. Sabouraudia. 10:152-156.

38. Juers, J. A., M. Rogers, J. B. McCurdy, and W. W. Cook. 1976. Enhancement of bactericidal capacity of alveolar macrophages by human alveolar lining material. J. Clin. Invest. 58:271-275.

39. LaForce, F. M., W. J. Kelly, and G. L. Huber. 1973. Inactivation of staphylococci by alveolar macrophages with preliminary observations on the importance of alveolar lining material. Amer. Rev. Respir. Dis. 108:784-790.

40. Gale, G. R., and A. M. Welch. 1961. Studies of opportunistic fungi. I. Inhibition of Rhizopus oryzae by human sera. Am. J. Med. Sci. 45:604-612.

41. Owens, A. W., M. S. Hacklette, and R. D. Baker. 1965. An antifungal factor in human serum. I. Studies of Rhizopus rhizopodiformis. Sabouraudia. 4:179-186.

42. Bauer, H., J. F. Flanagan, and W. H. Sheldon. 1956. The effects of metabolic alterations on experimental Rhizopus oryzae (mucormycosis) infection. Yale J. Biol. Med. 29:23-32. 